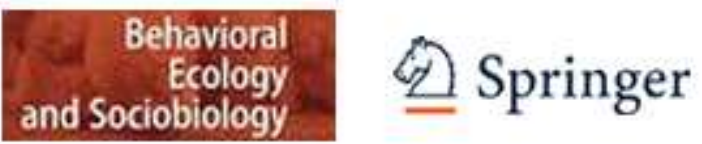

\title{
Determinants of multiple central-place territory use in wild young-of-the-year Atlantic salmon (Salmo salar)
}

\begin{tabular}{|r|l|}
\hline Journal: & Behavioral Ecology and Sociobiology \\
\hline Manuscript ID: & BES-10-0066.R1 \\
\hline Manuscript Type: & Original Paper \\
\hline $\begin{array}{r}\text { Date Submitted by the } \\
\text { Author: }\end{array}$ & $\mathrm{n} / \mathrm{a}$ \\
\hline Complete List of Authors: & $\begin{array}{l}\text { Steingrímsson, Stefán; Holar University College } \\
\text { Grant, James; Concordia University, Department of Biology }\end{array}$ \\
\hline Keywords: & $\begin{array}{l}\text { foraging mode, home range, invertebrate drift, mobility, stream } \\
\text { ecology, water current velocity }\end{array}$ \\
\hline
\end{tabular}

\section{5 scholarONE \\ Manuscript Central}


4 Determinants of multiple central-place territory use in wild young-of-the-year Atlantic

5 salmon (Salmo salar)

6

9 Stefán Ó. Steingrímsson ${ }^{*}$ and James W.A. Grant

10 Department of Biology, Concordia University, 7141 Sherbrooke Street W, Montréal, Québec,

11 H4B 1R6, Canada

12

13

14 *Correspondence: Stefán Ó. Steingrímsson, Hólar University College, Saudarkrokur, IS-551,

15 Iceland. E-mail: stefan@ holar.is, Telephone: +354-455-6387, Fax: +354-455-6381 
16 Abstract Patterns of space use provide key insights into how animals exploit local resources,

17 and are linked to both the fitness and distribution of individuals. We studied territory size,

18 mobility and foraging behavior of young-of-the-year Atlantic salmon Salmo salar in relation to

19 several key environmental factors in Catamaran Brook, New Brunswick, Canada. The 50 study

20 fish were all multiple central-place foragers (i.e. alternated among several sit-and-wait foraging

21 stations) and showed great variability in territory size and the total distance traveled within the

22 territories. Territory size increased with the mean distance traveled between consecutive foraging

23 stations, the number of stations visited and the mean foraging radius. Fish also varied greatly in

24 how much of the total travel distance was associated with foraging at a station (14.8-91.8\%)

25 versus switching among stations (4.6-84.3\%). As predicted, fish in slow-flowing waters, where

26 drifting prey were scarce, used larger multiple central-place territories than individuals in faster,

27 more productive waters. Interestingly, however, the most mobile fish did not inhabit slow-

28 running waters as predicted, but were found at intermediate (optimal) water current velocities.

29 Hence, our study suggests that among some multiple central-place foragers, increased mobility

30 may not only serve to increase prey encounter rate, but may reflect an attempt to patrol territories

31 in favourable habitats. Further studies are needed to determine the generality and the ultimate

32 benefits of multiple central-place space use among stream-dwelling fish and other animals.

34 Keywords foraging mode, home range, invertebrate drift, mobility, stream ecology, water

35 current velocity 


\section{Introduction}

Animals exhibit great variability in local space-use patterns, which in turn provide important insights into how individuals select, exploit and partition habitats and prey resources (Adams 2001; Helfman 1990; Sutherland 1996). For example, territories vary in size and the degree to which they are defended (Grant 1997), and thus influence food availability (Stamps 1984; Stamps and Eason 1989), the cost of defending an area (Davies and Houston 1984) and local

43 population density (Patterson 1980). Similarly, at local scales, individuals may vary in foraging

44 mode from sit-and-wait foragers, which search for prey from a stationary position, to cruising

45 foragers, which actively search for food (McLaughlin 1989; Pianka 1966; Schoener 1971). In

46 these situations, foraging mobility may affect prey encounter rate (Grant and Noakes 1987) and

47 the cost of exploiting a particular area (De Kerckhove et al. 2006), which together shape habitat use and population distribution (Sutherland 1996). In summary, territoriality, foraging and mobility play a vital role in shaping individual fitness (e.g. growth) and population structure. Local space-use patterns can be affected by a range of ecological variables (Grant 1997;

51 Helfman 1990). For example, many studies suggest animals occupy smaller and more easily

52 defendable territories when prey is dense and rapidly renewable (Davies and Houston 1984;

53 Grant et al. 1992), the same conditions under which ectothermal animals are expected to adopt a 54 sit-and-wait foraging mode (Helfman 1990; but see Huey and Pianka 1981). In addition, animals 55 are believed to adopt a sit-and-wait foraging mode when prey are mobile or spatially predictable, 56 but cruise for prey when they are sedentary or spatially unpredictable (Helfman 1990; Huey and

57 Pianka 1981). Hence, the literature suggests that territory size and foraging mobility may show a 58 coordinated response to different ecological conditions. However, although cruising foragers are 
59 often assumed to travel more widely than sit-and-wait foragers (e.g., Huey and Pianka 1981),

60 surprisingly few studies systematically examine how foraging mobility relates to local space-use

61 patterns and territory size (but see e.g., Ford 1983; Katano 1996).

62 Freshwater fishes and salmonids in particular, are an excellent model system for studying

63 the effects of environmental factors on local space use, because they exhibit great variability in

64 territorial and foraging behavior in the wild (Grant and Noakes 1987; Katano 1996; Nakano et al.

65 1999). In fast-running waters, where drifting invertebrates provide a spatially predictable, rapidly

66 renewing and abundant prey resource, stream-dwelling salmonids typically sit-and-wait and

67 intercept mobile prey from a centrally-placed foraging station (Grant et al. 1989; Kalleberg

68 1958). Intuitively, because the space use of these fish is constrained by repeated returns to the

69 same central-place location, they are often viewed as sedentary and as using small territories (but

70 see Steingrímsson and Grant 2008). In slow-running waters and lakes, however, fish may cruise

71 over large areas, as they specialize on sedentary or patchy food, such as benthic or planktonic

72 invertebrates (Biro et al. 1997; Katano 1996; McLaughlin et al. 1992; Minns 1995). Social status

73 can also influence local space use of stream-salmonids. Dominant individuals adopt sit-and-wait

74 foraging as they defend the best feeding positions where fast water flow provides abundant

75 drifting prey, whereas subordinate fish travel widely where less prey are available (Grant and

76 Noakes 1988; Nakano 1995; but see Martin-Smith and Armstrong 2002).

77 To date, several studies show that salmonid territories tend to be smaller in faster waters

78 where drifting prey is more abundant (Keeley and Grant 1995; McNicol and Noakes 1984; but

79 see Dill et al.1981). Similarly, foraging mode has been demonstrated to vary between species

80 (Ferguson and Noakes 1983; Nakano et al. 1999), between lake and stream populations of the

81 same species (Biro and Ridgway 1995), and between conspecific individuals found in slow- and 
82 faster-running waters of the same stream (Grant and Noakes 1987; McLaughlin et al. 1992). To

83 date, however, studies on salmonids rarely examine how territory size relates to foraging mode

84 and mobility; in part because estimates of territory size are typically confined to sit-and-wait

85 individuals that forage from a single central-place (see Steingrímsson and Grant 2008). This is

86 especially true for young-of-the-year (YOY) fish, which can be difficult to tag and follow in

87 natural settings (see Bachman 1984; Nakano 1995 for studies on older fish).

In this paper, we adapt general predictions on how space use relates to water current

89 velocity and prey abundance and apply them to YOY Atlantic salmon, which typically sit-and-

90 wait for prey, but can be defined as multiple central-place (MCP) foragers because they rotate

91 among several foraging stations (Steingrímsson and Grant 2008; see Chapman et al. 1989;

92 Covich 1976; McLaughlin and Montgomerie 1989 for other MCP animals). We predict that fish

93 will (i) use smaller territories, (ii) visit fewer foraging stations, and (iii) be less mobile, as current

94 velocity and the abundance of drifting prey increase. Second, with increasing current velocity

95 and drift abundance, fish will (i) travel shorter distances on each foraging attempt, (ii) forage

96 more frequently, and (iii) be less likely to attack benthic prey. Finally, we expect YOY found at

97 the most preferred current velocity $\left(6-24 \mathrm{~cm} \cdot \mathrm{s}^{-1}\right.$; Girard et al. 2004) to be the most aggressive and

98 grow fastest (Grant and Noakes 1988; but see Martin-Smith and Armstrong 2002).

99 To test these predictions, we observed the local space use of 50 tagged YOY Atlantic

100 salmon in a natural stream, and measured habitat features of their territories. Below, we first

101 describe the variability in space use found among our study fish, and then examine whether and

102 how territory size relates to foraging behavior and mobility. Finally, we test if, and how space

103 use is associated with water current velocity, prey availability and other key ecological variables. 


\section{Materials and methods}

106

107 Study population, sampling surveys, body size and growth

108

109 We studied YOY Atlantic salmon at 10 study sites in Catamaran Brook in New Brunswick in

1102000 (see Cunjak et al. 1993 and Steingrímsson and Grant 2003 for details on the stream biota

111 and the location of the study sites, respectively). Initially, 90 fish were captured, tagged and

112 measured for fork length (range: $27.3-40.6 \mathrm{~mm}$ ) in two snorkeling surveys on 25 June to 4 July,

113 and 12-13 July. Once we finished the space-use observations for all focal fish (see below), we

114 measured all tagged fish found in the study sites in two final snorkeling surveys on 20-23 August

115 and 11-12 September. In general, we tried to tag and observe fish in the complete range of

116 habitats used by YOY salmon in terms of water current velocity and depth. We described the

117 patterns of MCP territory size and defense for the same fish in Steingrímsson and Grant (2008).

118 Because we did not measure fish on the exact day of their space-use observation, we

119 estimated fork length of each fish on the day of observation by assuming a linear increase in fork

120 length between the capture surveys closest in time; one preceding and the other subsequent to the

121 observation date (Steingrímsson and Grant 2008). Growth rate was measured as (Fork length final $_{\text {- }}$

122 Fork length initial $) \cdot\left(\right.$ Day of year final $_{-}$Day of year initial $^{-1}\left(\right.$ unit $=\mathrm{mm} \cdot$ day $\left.^{-1}\right)$. Because most fish were

123 observed between the second (12-13 July) and the third (20-23 August) survey, and because

124 growth rate varied slightly between different time periods, only fish found in both these surveys

125 were used to test if and how growth changed across current velocities.

127 Observations of space use 
129 We observed the space use of 50 tagged individuals via snorkeling from 3 July to 17 August, 130 2000. Typically, fish were monitored for two 10-min periods in the early afternoon, and another 131 two 10-min periods later that same afternoon, yielding 40-min of data for each fish collected 132 between 1330-1850 h. After identifying the focal fish, we waited at least 5 min before each 10133 min period to avoid disturbance. For each territory, we recorded the location of foraging stations, 134 the direction (1-12 o'clock) and the estimated distance (in body lengths) of foraging attempts, the 135 location of aggressive acts, and if the focal fish was chased by an intruder. We estimated various 136 aspects of space use by creating a simple $\mathrm{x}-\mathrm{y}$ coordinate system for each study site, and mapping 137 each territory using ArcView GIS 3.2 in conjunction with the Animal Movement extension 138 (Hooge and Eichenlaub 2000). Territory size was estimated via the minimum convex polygon 139 method based on all spatial coordinates $\left(\mathrm{MCP}_{100 \%}\right)($ Schoener 1981). More details on the 140 measurement and estimation of space use are reported in Steingrímsson and Grant (2008). 141 Because of rapid changes in the behavior of the study fish, we could not record every 142 behavioral event for all 50 fish. We thus gave priority to recording the location of all foraging 143 stations visited (because these greatly affect estimates of territory size), and the location of all 144 aggressive acts (because these events are rare); these variables were recorded consistently over 145 the 40-min observation. We estimated the distance and direction of as many foraging attempts as 146 possible during the first 30 minutes, whereas during the last 10-min period we only estimated

147 foraging rate. Finally, we counted switches between foraging sites and estimated the mean and 148 total distance allocated toward switching for fish using only those 10 -min periods in which we 149 recorded all switches between stations.

150 Movement within territories was associated with four activities; $(i)$ foraging at a station, 
151 (ii) switching between foraging stations, (iii) attacking intruding fish, and (iv) fleeing from an 152 intruder. First, the distance traveled while foraging at a station was calculated as the number of 153 foraging attempts $\times 2 \times$ the mean foraging radius; hence, each foraging bout included a direct

154 return to the same station. Second, we estimated the distance traveled while switching based on 155 the number of switches $\times$ the mean distance traveled between consecutive stations. Finally, the 156 distance traveled while chasing and fleeing from an intruder was calculated as the frequency of

157 these events $\times 2 \times$ the mean aggressive radius. Because focal fish rarely fled from an intruder and 158 because we did not estimate the mean fleeing distance, we assumed it equaled the mean 159 aggressive radius.

161 Habitat and food abundance

162

163 For each fish, current velocity and water column depth were measured at, and averaged across

164 the five stations where most foraging attempts were recorded. If a fish visited fewer than five 165 stations, we measured the habitat at all stations visited. We measured current velocity at $40 \%$ of 166 the total depth (measured from the bottom) with a Marsh-McBirney meter (Model 201D; Marsh167 McBirney, 4539 Metropolitan Ct., Frederick, MD 21704, U.S.A.). Water temperature was 168 measured before and after the 20 min of observation in the early and late afternoon, respectively. 169 Because of time constraints, we did not sample invertebrate drift at each of the 50 170 territories, but predicted drift abundance at each territory using a multiple regression model 171 established for 30 drift samples, collected in the 10 study sites on three occasions (22-23 July, 81729 August, and 4-5 September) over the season. We sampled drift by placing a 1-m long drift net 173 (mesh size $=300 \mu \mathrm{m})$ with a metal frame opening $(15.2 \times 23 \mathrm{~cm})$, haphazardly at the initial 
174 location of one of the 90 tagged YOY salmon; no location was sampled more than once. We

175 varied the sampling time depending on how fast drift accumulated in the net (mean $=49 \mathrm{~min}$,

176 range $=15-120 \mathrm{~min})$. For each sample, we recorded the time and day of sampling, water

177 temperature, current velocity (measured in the center of the net opening) and water depth at the

178 sampling location. Samples were only collected during daylight hours (from $1325 \mathrm{~h}$ to $1845 \mathrm{~h}$ ).

179 Each drift sample was preserved in $10 \%$ buffered formalin and processed at Concordia

180 University. First, we separated intact organisms from other drifting material and counted all

181 organisms within the size range of edible prey ( $>99 \%$ of the total number) for YOY Atlantic

182 salmon (Keeley and Grant 1997). Second, we obtained the dry weight of each sample by placing

183 it in an oven at $50^{\circ} \mathrm{C}$ for $72 \mathrm{~h}$ (Merritt and Cummins 1978), then moving it to a desiccator, and

184 weighing it once on three consecutive days until the weight was stable $( \pm 0.0001 \mathrm{~g})$. The number

185 and dry weight of drifting prey were prorated to the area of the drift net frame (if not completely

186 submerged) and to a fixed time of 20 minutes. Because the numbers and dry weights of drift

187 samples were highly correlated [linear regression: $\log _{10}$ drift dry weight $\left(\mathrm{mg} \cdot 20 \mathrm{~min}^{-1}\right)=-1.710+$

$1881.032 \log _{10}$ drift number $\left(\right.$ no. $\left.\left.20 \mathrm{~min}^{-1}\right), r^{2}=0.881, n=30, p<0.001\right]$, we only report numbers

189 hereafter. Finally, we established a multiple regression model based on the sampling date and

190 measured habitat features to predict the invertebrate drift rate at the 50 territories. Overall, the

191 number of prey increased with current velocity, but decreased as the summer progressed

192 [multiple regression: $\log _{10}$ invertebrate drift (no. organisms $\cdot$ area of drift net opening $\left.{ }^{-1} \cdot 20 \mathrm{~min}^{-1}\right)=$

$1934.431+1.345 \log _{10}$ current velocity $\left(\mathrm{ms}^{-1}\right)-0.009$ day of year, $\left.r^{2}=0.918, n=30, p<0.001\right]$.

194 Neither water temperature (partial $p=0.231$ ), water depth (partial $p=0.727$ ), nor time of day

195 (partial $p=0.300$ ) added significantly to this model. Hence, we predicted the drift rate at each

196 territory based on the mean current velocity at the territory and the Julian date of the observation. 
198 Statistical analysis

200 To facilitate the analysis, we applied a few general rules. First, because drift rate was derived

201 from, and strongly related to current velocity (see above), and because space use changed in an

202 identical manner in response to both variables, we only report on current velocity as a predictor

203 hereafter. Second, because we did not always expect current velocity to associate with space use

204 in a linear manner, we tested for it’s effect both via a simple linear regression, and by adding a

205 quadratic component to the model; the best model (with the lowest $\mathrm{AIC}_{\mathrm{c}}$ value) was selected

206 using the Akaike's information criteria (Motulsky and Christopoulos 2004). Third, because water

207 depth, water temperature and fork length may also influence space use, we tested for their effect

208 along with current velocity via multiple regression. Overall, these additional variables had minor

209 effects on the $p$-value obtained for current velocity, and never altered whether current velocity

210 was better associated with space use in a linear or curvilinear manner. Because we do not put

211 forward a priori hypotheses on the effect of water depth, water temperature and fork length on

212 space use in stream-salmonids, we compared partial $p$-values for these variables to a Bonferroni

213 corrected significance level ( $\alpha$-value) of 0.005 (unplanned tests for eleven space use variables for

214 each correlate $=0.05 / 11)$. Where necessary, variables were $\log _{10^{-}}$or square-root transformed.

\section{Results}

218 Variability in territory use 
220 The 50 YOY Atlantic salmon monitored in this study (mean fork length $=4.30 \mathrm{~cm}$, range $=2.99$ -

221 5.24) exhibited great variability in local space-use patterns. Over the 40-min observation, focal

222 fish used territories $\left(\mathrm{MCP}_{100 \%}\right.$ ), which ranged from $0.268 \mathrm{~m}^{2}$ to $4.469 \mathrm{~m}^{2}$ (mean, back-

223 transformed from $\log _{10}=0.932 \mathrm{~m}^{2}$ ) (Fig. 1abc), visited as few as 3, and as many as 26 foraging

224 stations (median $=12.5$ stations) (Fig. 2 in Steingrímsson and Grant 2008), and traveled within

225 their territory, a total distance ranging from 15.7 to $95.0 \mathrm{~m}$ (median $=39.3 \mathrm{~m})$ (Fig. 1def).

226 Further variability is revealed when the distance traveled by each fish is classified into

227 different behavioral activities (Table 1; Fig. 2). The distance traveled during foraging attempts

228 varied 6.0 fold, from $8.2 \mathrm{~m}$ to $49.6 \mathrm{~m}$ over 40 minutes. More impressively, the distance traveled

229 while switching between stations ranged 33.7 fold from $2.4 \mathrm{~m}$ to $79.2 \mathrm{~m}$ (Table 1 ). In terms of

230 frequency, YOY Atlantic salmon foraged, on average, 0.85 to 48 times at each station before

231 switching, which occurred as rarely as once every 10 minutes, and as often as once every 12.9

232 seconds (Table 1$)$. Together, foraging $($ mean $=48.9 \%$, range $=14.8-91.4 \%)$ and switching

233 stations $($ mean $=47.8 \%$, range $=4.6-84.3 \%)$, accounted for $96.6 \%$ of the total distance traveled,

234 whereas only limited distances were allocated towards chasing (mean $=3.0 \%$, range $=0-20.3 \%)$

235 or fleeing from (mean $=0.4 \%$, range $=0-1.8 \%$ ) intruders (Fig. 2).

236 Finally, the focal fish directed most of their foraging attempts toward prey drifting in the

237 water column (mean $=91.2 \%$ : range $=75.0-99.1 \%)$, and only few attempts towards the benthos

$238($ mean $=7.5 \%$; range $=0.0-25.0 \%)$ or the water surface $($ mean $=1.3 \%$; range $=0.0-12.1 \%)$.

240 Behavioral determinants of territory size

242 The size of the multiple central-place territories of YOY Atlantic salmon increased with the 
243 mean distance traveled between consecutive foraging stations $(p<0.001)$, the number of

244 stations visited within the territory $(p<0.001)$ and the mean foraging radius around these

245 stations $(p=0.019)$ (Table 2$)$. Neither foraging rate nor the rate at which individuals switched

246 stations was related to territory size (partial $p>0.05$ ). Finally, in two univariate analyses,

247 territory size increased with the distance traveled while switching stations (Pearson's $r=0.308, n$

$248=50, p=0.030$; both variables $\log _{10}$ transformed) but not with the total distance traveled

249 (Pearson's $r=0.206, n=50, p=0.151$; both variables $\log _{10}$ transformed). Hence, whether

250 territory size is significantly associated with fish mobility depends on our measure of mobility.

252 Ecological determinants of space use and growth

254 The 50 study fish were observed over a wide range of current velocities (mean $=0.159 \mathrm{~m} \cdot \mathrm{s}^{-1}$, 255 range $=0.012-0.362)$ and water depths $($ mean $=34.4 \mathrm{~cm}$, range $=14.6-78.7)$, but at a narrow 256 range in water temperatures $\left(\right.$ mean $=19.8^{\circ} \mathrm{C}$, range $\left.=17.5-22.5\right)$. Predicted drift rate at the 50 257 territories varied 99.7 fold from 0.9 to 89.7 invertebrates (mean $=30.0)$ drifting through an area 258 equal to the drift net frame $\left(15.2 \times 23 \mathrm{~cm}=349.6 \mathrm{~cm}^{2}\right)$ in 20 minutes.

259 Water current velocity was related to several components of space use in YOY Atlantic 260 salmon, but not always as expected (Fig. 3). First, as predicted, territory size decreased with 261 increasing current velocity $\left(\log _{10}\right.$ territory size $\mathrm{m}^{2}=0.301-0.886$ current velocity ${ }^{1 / 2} \mathrm{~m} \cdot \mathrm{s}^{-1}, r^{2}=$

$2620.119, n=50, p=0.014$ ) (Fig. 3a). Second, contrary to predictions, the number of stations visited 263 within a territory did not increase as current velocity decreased (no. of foraging stations $=9.516$ $264+8.573$ current velocity $\left.{ }^{1 / 2} \mathrm{~m} \cdot \mathrm{s}^{-1}, r^{2}=0.034, n=50, p=0.202\right)($ Fig. 3b). Third, the total distance 265 traveled within territories was best described by a curvilinear relationship, where fish traveled 
most at intermediate water current velocities $\left(\log _{10}\right.$ total distance traveled $\mathrm{m}=0.547+6.010$

267 current velocity ${ }^{1 / 2}-7.907$ current velocity $\left.\mathrm{m} \cdot \mathrm{s}^{-1}, r^{2}=0.298, n=50, p<0.001\right)($ Fig $3 \mathrm{c})$; this

268 contradicts the prediction that mobility should be greater in slow waters where drifting prey is

269 scarce. Overall, the results above were supported when the effects of current velocity on space

270 use were examined via multiple regression analysis. In no case did the inclusion of water depth,

271 water temperature and fork length, affect whether current velocity was significantly associated

272 with a given space-use component, or whether this relationship was better described in a linear or

273 curvilinear manner. Water depth was the only other correlate that was related to the components

274 of space use; fish in deep waters used significantly larger territories than those found in shallow

275 waters (partial $p=0.005$ ). Interestingly, the total distance traveled was not related to the size of

276 the focal fish (partial $p=0.315)$.

277 The influence of current velocity on space use was explored further by examining the

278 foraging and switching behavior of the study fish (Fig. 4). Overall, these two components of

279 behavior showed a similar response to current velocity, although these results were not always

280 predicted from MCP theory. First, as expected from the increased availability of drifting prey

281 and increased swimming costs, the mean foraging radius and the mean distance traveled between

282 consecutive stations decreased as current velocity increased $\left(\log _{10}\right.$ mean foraging radius $\mathrm{cm}=$

$2830.828-0.306$ current velocity ${ }^{1 / 2} \mathrm{~m} \cdot \mathrm{s}^{-1}, r^{2}=0.102, n=50, p=0.023 ; \log _{10}$ mean switching

284 distance $\mathrm{cm}=1.916-0.804$ current velocity $\left.{ }^{1 / 2} \mathrm{~m} \cdot \mathrm{s}^{-1}, r^{2}=0.370, n=50, p<0.001\right)(\mathrm{Fig}$. 4ad).

285 Second, as current velocity increased, both the foraging rate and the rate at which fish switched

286 between stations, increased initially and then leveled off and decreased slightly $\left(\log _{10}\right.$ foraging

287 attempts no. $\cdot 10 \mathrm{~min}^{-1}=0.809+4.355$ current velocity ${ }^{1 / 2}-5.359$ current velocity $\mathrm{m} \cdot \mathrm{s}^{-1}, r^{2}=$

$2880.348, n=50, p<0.001 ; \log _{10}$ station switches no. $\cdot 10 \mathrm{~min}^{-1}=-0.409+6.980$ current velocity $^{1 / 2}-$ 
2897.966 current velocity $\mathrm{m} \cdot \mathrm{s}^{-1}, r^{2}=0.174, n=50, p=0.011$ ) (Fig. 4be). These findings were

290 unexpected for the switching frequency because drift-feeding fish are predicted to be less mobile

291 in fast waters where prey is abundant. Third, the distance traveled during foraging attempts was

292 greatest at intermediate current velocities $\left(\log _{10}\right.$ distance traveled foraging $\mathrm{m} \cdot 40 \mathrm{~min}^{-1}=0.342+$

2935.215 current velocity $^{1 / 2}-6.928$ current velocity $\left.\mathrm{m} \cdot \mathrm{s}^{-1}, r^{2}=0.262, n=50, p<0.001\right)($ Fig. $4 \mathrm{c})$.

294 Similarly, the total distance moved between stations fit better to current velocity in a curvilinear

295 manner, although not significantly $\left(\log _{10}\right.$ distance traveled switching $\mathrm{m} \cdot 40 \mathrm{~min}^{-1}=0.251+5.323$

296 current velocity ${ }^{1 / 2}-6.752$ current velocity $\mathrm{m} \cdot \mathrm{s}^{-1}, r^{2}=0.078, n=50, p=0.147$ ) (Fig. 4f). A

297 multivariate approach did not alter how foraging and switching behavior was associated with

298 current velocity and only revealed one significant association with another potential predictor;

299 i.e., larger fish attacked prey at a greater distance (partial $p<0.001$ ). Finally, fish did not switch

300 to benthos in slow running waters as no association, neither linear $(p=0.780)$ nor curvilinear $(p$

$301=0.293$ ), was detected between the percent of benthic foraging and current velocity.

302 Our results were equivocal regarding the hypothesis that more aggressive individuals,

303 with greater growth potential, inhabit and defend territories in faster waters where drifting prey is

304 more abundant. Based on few aggressive acts per fish, aggression toward intruders was more

305 common at intermediate current velocities than in slow-running waters, but decreased again as

306 current velocity increased further $\left(\log _{10}\right.$ chase frequency no. $+1 \cdot 40 \mathrm{~min}^{-1}=-0.390+5.843$ current

307 velocity ${ }^{1 / 2}-8.189$ current velocity $\mathrm{m} \cdot \mathrm{s}^{-1}, r^{2}=0.128, n=50, p=0.041$ ) (Fig. 5a). Interestingly,

308 fish inhabiting fast water grew more slowly than those found in slow water (growth rate $\mathrm{mm}^{\circ} \mathrm{day}^{-}$

$309^{1}=0.448-0.184$ current velocity $\left.{ }^{1 / 2} \mathrm{~m} \cdot \mathrm{s}^{-1}, r^{2}=0.191, \mathrm{n}=38, p=0.006\right)($ Fig. $5 \mathrm{~b})$. The respective

310 multivariate analyses for aggression and growth found no significant effect of water temperature,

311 water depth and fork length (partial $p>0.3$ in all cases). 


\section{Discussion}

315 Patterns of territory use

317 Many stream fish adopt alternative foraging tactics as they either actively cruise for benthic or 318 patchy prey items (movers), or are relatively sedentary and ambush drifting prey via sit-and-wait

319 foraging tactics (stayers) (Grant and Noakes 1987; Katano 1996; McLaughlin et al. 1999). In this 320 study, however, YOY Atlantic salmon were best described as multiple central-place foragers, 321 which sit-and-wait for prey, rotate among several foraging stations, but rarely attack their prey 322 while moving (Steingrímsson and Grant 2008). Importantly, although our study fish do not 323 appear to be able to switch from sit-and-wait to cruising foraging, they exhibit considerable and 324 often unexpected variability in their territory use patterns.

325 First, YOY Atlantic salmon in Catamaran Brook use MCP territories that are very large 326 compared to typical single central-place territories defended by other YOY stream-dwelling 327 salmonids, and are also highly variable in size $\left(0.268-4.469 \mathrm{~m}^{2}\right)$ (see Steingrímsson and Grant 328 2008). Second, our study shows that stream salmonids can vary greatly in the number of foraging 329 stations visited within their territories (3-26 stations) (see Nakano 1995). Finally, in spite of 330 being predominately sit-and-wait foragers, the study fish were very mobile, traveling a total

331 distance of 15.7 to $95.0 \mathrm{~m}$ (median $=39.3 \mathrm{~m}=914$ body lengths $\cdot 40 \mathrm{~min}^{-1}$ ), of which $47.8 \%(4.6-$ $33284.3 \%$ ) was due to switching between foraging stations. In comparison, based on the mean radii 333 and the frequency of aggressive acts and foraging attempts initiated by a territorial stream-fish 334 from one foraging station (sensu Materials and methods), we estimate that YOY brook charr 
335 (Grant et al. 1989) and YOY rainbow trout (Keeley 2000) traveled on average 501 and 722 body

336 lengths in 40 minutes, respectively. Furthermore, YOY brook charr in two lakes, most of which

337 were cruising foragers, traveled a mean distance of 890 and 1187 body lengths in 40 minutes,

338 while searching for prey (estimated from Biro et al. 1997). Hence, MCP drift-feeding fish are

339 more mobile than single central-place foragers and may even travel similar distances to cruising

340 fish in lakes. Unfortunately, most studies on stream-salmonids focus on the energetic basis of

341 drift-feeding from a single focal point (e.g., Enders et al. 2003; Hughes et al. 2003), and the costs

342 and benefits associated with switching among several stations have received limited attention.

344 Ecological determinants of territory use

346 Because the use of multiple foraging stations among salmonids has received limited attention

347 (but see e.g. Nakano 1995), this study yields several novel findings on how their space-use

348 patterns relate to ecological conditions. First, in harmony with most single central-place studies

349 (Keeley 2000; McNicol and Noakes 1984; but see Dill et al.1981), MCP territories decreased in

350 size as current velocity and prey drift rate increased. In MCP territories, this decrease in size is

351 associated with a decrease in the distance traveled between consecutive foraging stations and a

352 shorter foraging radius in faster, more productive waters (Keeley 2000). Interestingly, although

353 fish that visit more foraging stations have larger territories, there is no evidence that they visit

354 fewer stations in faster water where drifting prey is abundant. In contrast, Nakano (1995) found

355 that among masu salmon (Oncorhynchus masou) in pools, dominant fish used one or few stations

356 where prey were abundant, while younger subordinate fish switched among several low-quality

357 stations. This discrepancy may be due to Nakano's (1995) fish forming space-related dominance 
358 hierarchies across year-classes in a habitat where the best feeding sites (and food resources) are

359 relatively predictable and clumped in space. YOY Atlantic salmon, however, are typically found

360 in a territorial mosaic (Kalleberg 1956), where the input and distribution of drifting prey may

361 play a less obvious role in shaping social status and space use.

362 Unexpectedly, and irrespective of how mobility was measured, YOY Atlantic salmon

363 were not most mobile in slow-running waters where drifting prey is scarce. Instead, the most

364 mobile fish were found at intermediate current velocities; this trend emerged when we examined

365 (i) the total distance traveled, (ii) the rate at which YOY salmon switched between stations (rate

366 of movement, sensu Ford 1983), but not significantly so for (iii) the distance traveled while

367 switching. These findings, coupled with the fact that fish in slow waters did not forage more on

368 the benthos, suggest that mobility in YOY salmon was not primarily associated with seeking out

369 alternative prey where drifting invertebrates were rare (but see Armstrong et al. 1999). In this

370 study, however, benthic foraging was greater (7.5\%) than in an earlier study on Atlantic salmon

371 in Catamaran Brook $(<1 \%)$, where fish used fewer stations (Keeley and Grant 1995). Hence, the

372 link between benthic foraging and multiple central-place space use may warrant further study.

373 Why YOY Atlantic salmon travel more between stations at intermediate water current

374 velocities remains unclear, but habitat selection and territorial behavior may play a role. First,

375 although YOY salmon in Catamaran Brook use a wide range of habitats, they show consistent

376 preferences for current velocities of $6-24 \mathrm{~cm} \cdot \mathrm{s}^{-1}$ (Girard et al. 2004; see also Morantz et al. 1987),

377 which match the intermediate current velocities used by the most mobile fish in this study (Fig.

378 4ef). Second, among drift-feeding fish, preferred current velocities generally represent higher

379 quality habitats, e.g. in terms of net energetic gain (Hill and Grossman 1993). Third, Johnsson et

380 al. (2000) showed that brown trout in preferred habitats defend their territories more intensively 
381 than those in low quality habitat; a similar trend emerged in this study as aggression is slightly

382 more frequent at intermediate current velocities. Consequently, because our fish rarely attack

383 intruders across their large MCP areas (Steingrímsson and Grant 2008), rapid switches among

384 stations at optimal water currents, may indicate more patrolling of territories. Although patrolling

385 increases travel costs of territory holders, it may also reduce the traffic of intruders immediately

386 upstream of many foraging stations, where a significant portion of the drifting prey may emerge

387 from the benthos (Elliott 2002; McIntosh and Townsend 1998; see Steingrímsson and Grant

388 2008). Importantly, our data suggest that YOY Atlantic salmon occupying preferred current

389 velocities do not grow faster than fish in other habitats (see also Girard et al. 2004). Obviously,

390 the above ideas need to be verified in future studies.

391 Ecological variables other than current velocity and invertebrate drift had limited effects

392 on the space use of YOY salmon. Not surprisingly, foraging radius was positively related to fork

393 length (see e.g. Elliott 1990; Grant et al. 1989), in part because larger fish are better swimmers

394 and may see farther (Dunbrack and Dill 1983). The study fish also used larger territories in

395 deeper water, perhaps because they tend to attack prey at a greater distance, and travel longer

396 distances between consecutive stations. To date, however, any explanations on the ultimate

397 causes for this trend would remain speculative.

398

399 Implications for salmonids and MCP foragers

400

401 Multiple central-place behavior of YOY Atlantic salmon adds a new dimension to the existing

402 literature on how space use relates to environmental conditions, and how these factors combine

403 to shape individual fitness and population dynamics of stream-dwelling salmonids. First, large 
404 MCP territories, although not defended as efficiently as smaller territories, suggest that territorial 405 behavior plays an important role during competition for food and space, even at low population 406 densities where habitats appear not to be highly saturated (see discussion in Steingrímsson and 407 Grant 2008). Second, this study shows that salmonid species differ in the foraging mode they 408 typically adopt, and the flexibility they exhibit in response to different ecological conditions. For 409 example, brook charr (Salvelinus fontinalis) (Biro and Ridgway 1995; Grant and Noakes 1987; 410 McLaughlin et al. 1999), Dolly Varden charr (Salvelinus malma) (Fausch et al. 1997) and coho 411 salmon (Oncorhynchus kisutch) (Puckett and Dill 1985) can adopt both a sit-and-wait and an 412 active foraging mode, where the latter is associated with utilizing benthic (Fausch et al. 1997) or 413 pelagic prey (McLaughlin et al 1999) in slow waters where drifting prey is rare. Other species, 414 such as white spotted charr (Salvelinus leucomaenis) (Fausch et al. 1997) and Atlantic salmon 415 (Nislow et al. 1998; but see this study), may respond to reduced drift via increased benthic 416 feeding, but without the corresponding switch to active search (but see Armstrong et al. 1999).

417 Although this study indicates that YOY Atlantic salmon are mostly sit-and-wait foragers, it 418 demonstrates that "less flexible" salmonids, may still exhibit great variability in their space-use 419 patterns, e.g. in the number of foraging stations visited and mobility. Finally, this study suggests 420 that YOY salmon may grow faster, or as fast (Girard et al. 2004) in slow waters where drift421 feeding is presumably less beneficial, without switching to alternative prey such as benthos. To date, multiple central-place foraging has been primarily viewed as a foraging tactic 423 used among mammals and birds to increase encounter rate with a depletable food supply while 424 minimizing travel costs (Chapman et al. 1989; McLaughlin and Montgomerie 1989). This study, 425 however, differs in two important ways from earlier MCP studies, because YOY Atlantic salmon 426 (i) defend territories and (ii) feed on drifting prey, often viewed as a rapidly-renewing resource 
427 (Sutherland 1996). Hence, this study extends MCP theory to situations where foraging from

428 multiple sites does not obviously increase encounter rate or decrease travel costs, and may rather

429 be related to how intensively home ranges are patrolled and defended (sensu Mitani and Rodman

430 1979; Paton and Carpenter 1984). The generality and the ultimate causes of multiple central-

431 place foraging among stream-dwelling fish and other animals warrant further study.

433 Acknowledgements We thank Cindy Breau for her help in collecting the data, Rick Cunjak,

434 Peter Hardie, Danielle Caisse and coworkers for the logistical support at Catamaran Brook, and

435 Grant E. Brown, Edward J. Maly, and Donald L. Kramer for comments on an earlier version of

436 the paper. This study was financed by a Concordia University Graduate Fellowship, a Concordia

437 University International Tuition Fee Remission Award and a Garnet Strong Scholarship awarded

438 to S.Ó.S., and a Discovery Grant issued to J.W.A.G. from the Natural Sciences and Engineering

439 Research Council of Canada. When finishing the manuscript, S.Ó.S. was employed by Hólar

440 University College. Our research plan was approved by the Concordia University Animal

441 Research Ethics Committee and conforms to the policies of the Canadian Council on Animal

442 Care. This paper is contribution no. 104 of the Catamaran Brook Habitat Research Project. 


\section{References}

444

Adams ES (2001) Approaches to the study of territory size and shape. Ann Rev Ecol Syst 2001: $277-303$

Armstrong JD, Huntingford FA, Herbert NA (1999) Individual space use strategies of wild juvenile Atlantic salmon. J Fish Biol 55: 1201-1212

Bachman RA (1984) Foraging behavior of free-ranging wild and hatchery brown trout in a stream. Trans Am Fish Soc 113: 1-32

Biro PA, Ridgeway MS (1995) Individual variation in foraging movements in a lake population of young-of-the-year brook charr (Salvelinus fontinalis). Behaviour 132: 57-74

Biro PA, Ridgeway MS, Noakes DLG (1997) The central-place territorial model does not apply to space-use by juvenile brook charr Salvelinus fontinalis in lakes. J Anim Ecol 66: 837845

Chapman CA, Chapman LJ, McLaughlin RL (1989) Multiple central place foraging by spider monkeys: travel consequences of using many sleeping sites. Oecologia 79: 506-511

Covich AP (1976) Analysing shapes of foraging areas: some ecological and economic theories. Ann Rev Ecol Syst 7: 235-257

Cunjak RA, Caissie D, El-Jabi N, Hardie P, Conlon JH, Pollock TH, Giberson DJ, KomadinaDouthwright S (1993) The Catamaran Brook (New Brunswick) habitat research project: biological, physical and chemical conditions (1990-1992). Can Tech Rep Fish Aquat Sci 1914

Davies NB, Houston AI (1984) Territory economics. In: Krebs JR, Davis NB (eds) Behavioural ecology: an evolutionary approach, 2nd edn, Sinauer Associates Inc, Sunderland, 
Massachusetts, pp 148-169

467

468

De Kerckhove D, McLaughlin RL, Noakes DLG (2006) Ecological mechanisms favouring behavioural diversification in the absence of morphological diversification: a theoretical examination using brook charr (Salvelinus fontinalis). J Anim Ecol 75: 506-517

Dill LM, Ydenberg RC, Fraser AHG (1981) Food abundance and territory size in juvenile coho salmon (Oncorhynchus kisutch). Can J Zool 59: 1801-1809

Dunbrack RL, Dill LM (1983) A model of size dependent surface feeding in a stream dwelling salmonid. Env Biol Fish 8: 203-216

Elliott JM (1990) Mechanisms responsible for population regulation in young migratory trout, Salmo trutta. III. the role of territorial behaviour. J Anim Ecol 59: 803-818

Elliott JM (2002) Time spent in the drift by downstream-dispersing invertebrates in a Lake District stream. Freshw Biol 47: 97-106

Enders EC, Boisclair D, Roy AG (2003) The effect of turbulence on the cost of swimming for juvenile Atlantic salmon (Salmo salar). Can J Fish Aquat Sci 60: 1149-1160

Fausch KD, Nakano S, Kitano S (1997) Experimentally induced foraging mode shift by sympatric charrs in a Japanese mountain stream. Behav Ecol 8: 414-420

Ferguson MM, Noakes DLG (1983) Movers and stayers - genetic-analysis of mobility and positioning in hybrids of lake charr, Salvelinus-namaycush, and brook charr, S. fontinalis (Pisces: Salmonidae). Behav Genet 13: 213-222

Ford RG 1983. Home range in a patchy environment: optimal foraging predictions. Amer Zool 23: $315-326$

Girard I, Grant JWA, Steingrímsson SÓ (2004) Foraging, growth and loss rate of young-of-theyear Atlantic salmon (Salmo salar) in relation to habitat use in Catamaran Brook, New 
Grant JWA (1997) Territoriality, In: Godin J-GJ (ed) Behavioural ecology of teleost fishes, Oxford University Press, Oxford, pp 81-103

Grant JWA, Chapman CA, Richardson KS (1992) Defended versus undefended home range size of carnivores, ungulates and primates. Behav Ecol Sociobiol 31: 149-161

Grant JWA, Noakes DLG (1987) Movers and stayers: foraging tactics of young-of-the-year brook charr, Salvelinus fontinalis (Pisces, Salmonidae). J Anim Ecol 56: 1001-1013

Grant JWA, Noakes DLG (1988) Aggressiveness and foraging mode of young-of-the-year brook charr, Salvelinus fontinalis (Pisces, Salmonidae). Behav Ecol Sociobiol 22: 435-445

Grant JWA, Noakes DLG, Jonas KM (1989) Spatial distribution of defence and foraging in young-of-the-year brook charr, Salvelinus fontinalis. J Anim Ecol 58: 773-784

Helfman GS (1990) Mode selection and mode switching in foraging animals. Adv Study Behav

502

503

504

19: $249-298$

Hill J, Grossman GD (1993) An energetic model of microhabitat use for rainbow trout and rosyside dace. Ecology 74: 685-698

Hooge PN, Eichenlaub B (2000) Animal movement extension to Arcview, ver 2.0. Alaska Science Center - Biological Science office, US Geological Survey, Anchorage, Alaska

Huey RB, Pianka ER (1981) Ecological consequences of foraging mode. Ecology 62: 991-999

Hughes NF, Hayes JW, Shearer KA, Young RG (2003) Testing a model of drift-feeding using three-dimensional videography of wild brown trout, Salmo trutta, in a New Zealand river. Can J Fish Aquat Sci 60: 1462-1476

Johnsson JI, Carlsson M, Sundström LF (2000) Habitat preference increases territorial defence in brown trout (Salmo trutta). Behav Ecol Sociobiol 48: 373-377 
512 Kalleberg H (1958) Observations in a stream tank of territoriality and competition in juvenile

513 salmon and trout (Salmo salar L. and S. trutta L.). Rep Inst Freshw Res Drottningholm,

$514 \quad 39: 55-98$

515 Katano O (1996) Foraging tactics and home range of dark chub in a Japanese river. Oecologia, $516 \quad 106: 199-205$

517 Keeley ER, Grant JWA (1995) Allometric and environmental correlates of territory size in 518 juvenile Atlantic salmon (Salmo salar). Can J Fish Aquat Sci 52: 186-196

519 Keeley ER, Grant JWA (1997) Allometry of diet selectivity in juvenile Atlantic salmon (Salmo 520 salar). Can J Fish Aquat Sci 54: 1894-1902

521 Keeley ER (2000) An experimental analysis of territory size in juvenile steelhead trout. Anim Behav 59: 477-490

Martin-Smith KM, Armstrong JD (2002) Growth rates of wild stream-dwelling Atlantic salmon correlate with activity and sex but not dominance. J Anim Ecol 71: 413-423

McIntosh AR, Townsend CR (1998) Do different predators affect distance, direction, and destination of movements by stream mayfly. Can J Fish Aquat Sci 55: 1954-1960

McLaughlin RL (1989) Search modes of birds and lizards: evidence for alternative movement

McLaughlin RL, Ferguson MM, Noakes DLG (1999) Adaptive peaks and alternative foraging patterns. Am Nat 133: 654-670 tactics in brook charr: evidence of short-term divergent selection for sitting-and-waiting

532 McLaughlin RL, Grant JWA, Kramer DL (1992) Individual variation and alternative patterns of foraging movements in recently-emerged brook charr (Salvelinus fontinalis). Behaviour, 
535 McLaughlin RL, Montgomerie RD (1989) Brood dispersal and multiple central place foraging $536 \quad$ by Lapland longspur parents. Behav Ecol Sociobiol 25: 207-215

537 McNicol RE, Noakes DLG (1984) Environmental influences on territoriality of juvenile brook 538 charr, Salvelinus fontinalis, in stream environment. Env Biol Fish 10: 29-42

539 Merritt RW, Cummins KW (1978) An introduction to the aquatic insects of North America.

$540 \quad$ Kendall/Hunt, Iowa

541 Minns CK (1995) Allometry of home range size in lake and river fishes. Can J Fish Aquat Sci 52: $1499-1508$

543 Mitani JC, Rodman PS (1979) Territoriality: the relation of ranging pattern and home range size to defendability, with an analysis of territoriality among primate species. Behav Ecol Sociobiol 5: 241-251

Morantz DL, Sweeney RK, Shirvell CS, Longard DA (1987) Selection of microhabitat in summer by juvenile Atlantic (Salmo salar). Can J Fish Aquat Sci 44: 120-129

Motulsky H, Christopoulos A (2004) Fitting models to biological data using linear and nonlinear regression: A practical guide to curve fitting. Oxford University Press, Oxford

Nakano S (1995) Individual differences in resource use, growth and emigration under the influence of a dominance hierarchy in fluvial red-spotted masu salmon in a natural

553 Nakano S, Fausch KD, Kitano S (1999) Flexible niche partitioning via a foraging mode shift: a proposed mechanism for coexistence in stream-dwelling charrs. J Anim Ecol 68: 1079-

556 Nislow KH, Folt C, Seandel M (1998) Food and foraging behavior in relation to microhabitat use and survival of age-0 Atlantic salmon. Can J Fish Aquat Sci 55: 116-127 
558 Paton DC, Carpenter FL (1984) Peripheral foraging by territorial rufous hummingbirds: defense $559 \quad$ by exploitation. Ecology 65: 1808-1819

560 Patterson IJ (1980) Territorial behaviour and the limitation of population density. Ardea 68: 53$561 \quad 62$

562 Pianka ER (1966) Convexity, desert lizards, and spatial heterogeneity. Ecology, 47: 1055-1059.

563 Puckett KJ Dill LM (1985) The energetics of feeding territoriality in juvenile coho salmon

564 (Oncorhynchus kisutch). Behaviour 92: 97-111

565 Schoener TW (1971) Theory of feeding strategies. Ann Rev Ecol Syst 2: 369-404

566 Schoener TW (1981) An empirically based estimate of home range. Theor Pop Biol 20: 281-325

567 Stamps JA (1984) Growth costs of territorial overlap: experiments with juvenile lizards (Anolis 568 aeneus). 15: 115-119

569 Stamps JA, Eason PK (1989) Relationship between spacing behavior and growth rates: A field $570 \quad$ study of lizard feeding territories. 25: 99-107

571 Steingrímsson SÓ Grant JWA (2003) Patterns and correlates of movement and site fidelity in 572 individually tagged young-of-the-year Atlantic salmon (Salmo salar). Can J Fish Aquat $573 \quad$ Sci 60: 193-202

574 Steingrímsson SÓ Grant JWA (2008) Multiple central-place territories in young-of-the-year $575 \quad$ Atlantic salmon. J Anim Ecol 77: 448-457

576 Sutherland WJ (1996) From individual behaviour to population ecology. Oxford University $577 \quad$ Press, Oxford 
578 Table 1 Variability in space use associated with foraging from a station, switching between

579 foraging stations, and chasing intruding fish, by 50 young-of-the-year Atlantic salmon in

580 Catamaran Brook

\begin{tabular}{|c|c|c|c|c|}
\hline Variable & Mean & Median & Range & $\mathrm{CV}$ \\
\hline Distance traveled foraging $\left(\mathrm{m} \cdot 40 \mathrm{~min}^{-1}\right)$ & 19.4 & 15.6 & $8.2-49.6$ & 0.507 \\
\hline - Foraging rate (no. attempts $10 \mathrm{~min}^{-1}$ ) & 44.9 & 42.3 & $19.0-93.0$ & 0.349 \\
\hline - Mean foraging radius $(\mathrm{cm})$ & 5.3 & 4.9 & $3.6-12.2$ & 0.285 \\
\hline Distance traveled switching $\left(\mathrm{m} \cdot 40 \mathrm{~min}^{-1}\right)$ & 23.5 & 16.3 & $2.4-79.2$ & 0.852 \\
\hline - Switching frequency (no. $\left.\cdot 10 \mathrm{~min}^{-1}\right)$ & 14.4 & 9.7 & $1.0-46.5$ & 0.805 \\
\hline - Mean switching distance $(\mathrm{cm})$ & 43.0 & 41.0 & $22.3-117.0$ & 0.382 \\
\hline Distance traveled during chases $\left(\mathrm{m} \cdot 40 \mathrm{~min}^{-1}\right)$ & 1.3 & 1.0 & $0.0-6.1$ & 1.089 \\
\hline - Aggressive frequency (chases $40 \mathrm{~min}^{-1}$ ) & 3.4 & 3.0 & $0-11$ & 0.886 \\
\hline - Mean aggressive radius & 15.9 & 15.2 & $1.9-31.8$ & 0.409 \\
\hline
\end{tabular}


Table 2 Multiple regression model ${ }^{\mathrm{a}}$ describing the behavioral correlates of $\log _{10}$ territory size $\left(\mathrm{m}^{2}\right)$ in young-of-the-year Atlantic salmon using multiple foraging stations in Catamaran Brook

\begin{tabular}{|c|c|c|c|}
\hline Correlate & Slope & $r^{2}$ & $p$-value \\
\hline $\log _{10}$ mean switching distance $(\mathrm{cm})$ & 1.2407 & 0.622 & $<0.001$ \\
\hline Stations visited (no. $40 \mathrm{~min}^{-1}$ ) & 0.0273 & +0.171 & $<0.001$ \\
\hline $\log _{10}$ mean foraging radius $(\mathrm{cm})$ & 0.5225 & +0.013 & 0.019 \\
\hline Total number of observations (n) & -0.0007 & +0.016 & 0.047 \\
\hline Full model & -- & 0.822 & $<0.001$ \\
\hline
\end{tabular}

'The model was selected using the Akaike's information criteria; $\log _{10}$ foraging attempts (no. 10 $\left.\min ^{-1}\right)$ and $\log _{10}$ station switches (no. $10 \mathrm{~min}^{-1}$ ) were removed from the model. 


\section{Figure legends}

Fig. 1 Variability in the space-use patterns of YOY Atlantic salmon in Catamaran Brook. The $100 \%$ minimum convex polygon (wide solid line) encircles the location of all aggressive acts and foraging attempts (solid circle), the foraging stations visited (crossed circle), and the travel pattern (thin solid line) of selected individuals. The left column depicts (a) the smallest and (b) the largest territory, and (c) the frequency distribution of territory sizes. The right column depicts the fish that traveled (d) least and (e) most, and (f) the frequency of the total distances traveled in 40 minutes within the 50 territories

Fig. 2 Individual variability in the distance traveled within the territories of 50 YOY Atlantic salmon in Catamaran Brook. Each column shows one fish (1-50, in the order of observation), and indicates the percentage of the total distance traveled in 40 minutes, allocated toward switching between stations (grey), foraging attempts (empty), aggression toward intruding fish (hatched), and fleeing from intruders (dotted)

Fig. 3 The effect of water current velocity on (a) the territory size, (b) the number of foraging stations, and (c) the total distance traveled within territories of 50 YOY Atlantic salmon in Catamaran Brook. The equations best describing these relationships are represented either by a solid (significant) or dashed line (not significant). For visual clarity, transformed values on both axes were replaced with the original, back-transformed values. All dependent variables were estimated over 40 minutes 
Fig. 4 The influence of current velocity on foraging behavior (a, b, c) and switching between foraging stations (d, e, f) of 50 YOY Atlantic salmon in Catamaran Brook. The equations best describing these relationships are represented by a solid (significant) or dashed line (not significant).

Fig. 5 The association between current velocity and (a) the number of aggressive acts directed toward intruding fish and (b) the growth rate of YOY Atlantic salmon in Catamaran Brook. The solid lines represent the best fit to the data. Growth rate is measured between 12-13 July and 2023 August, 2000, and is only reported for fish caught in both surveys 

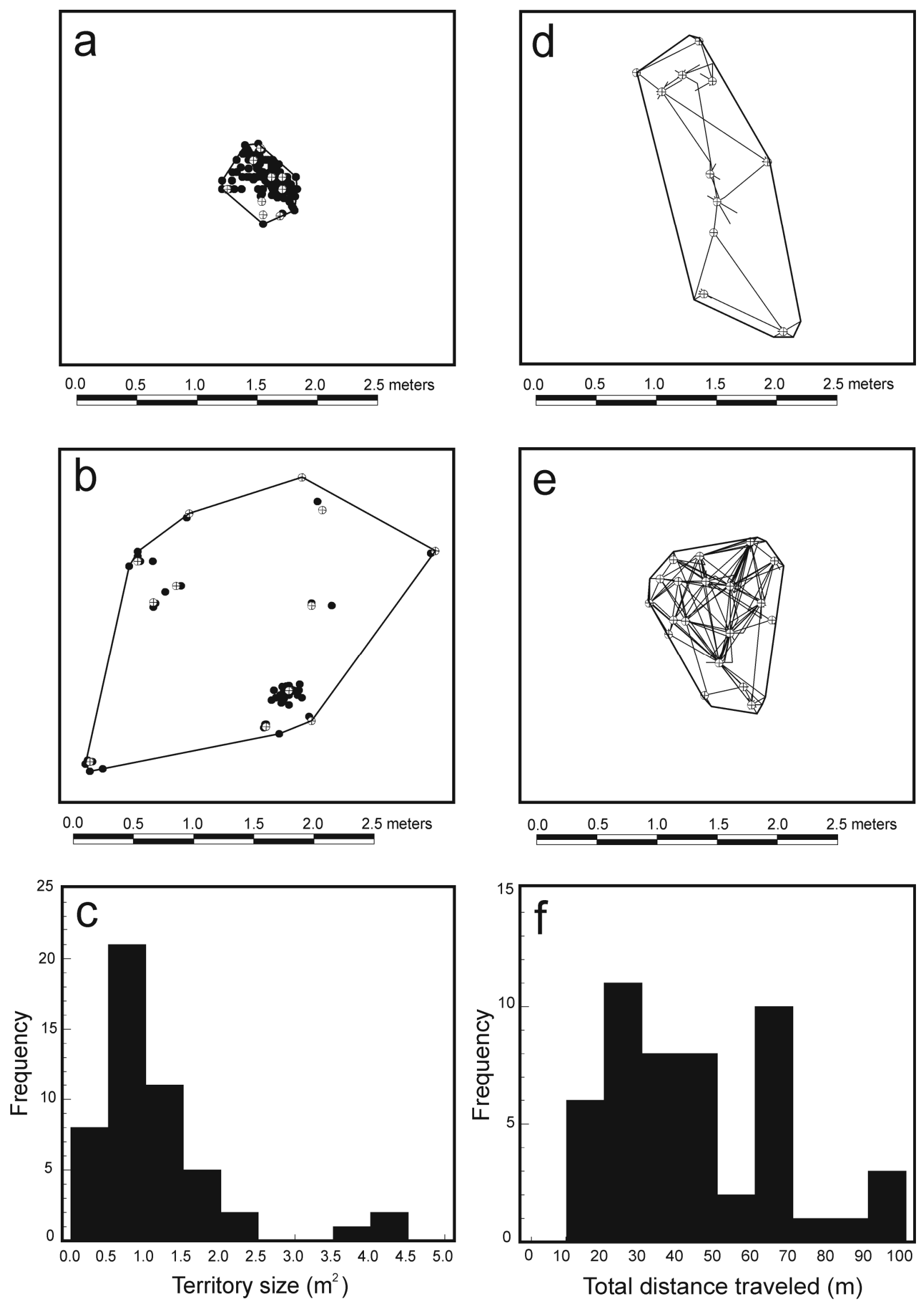


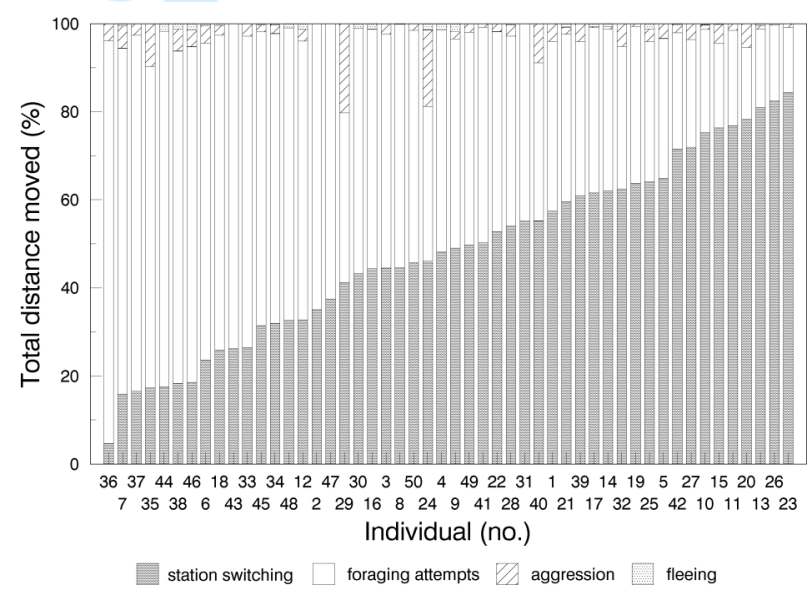



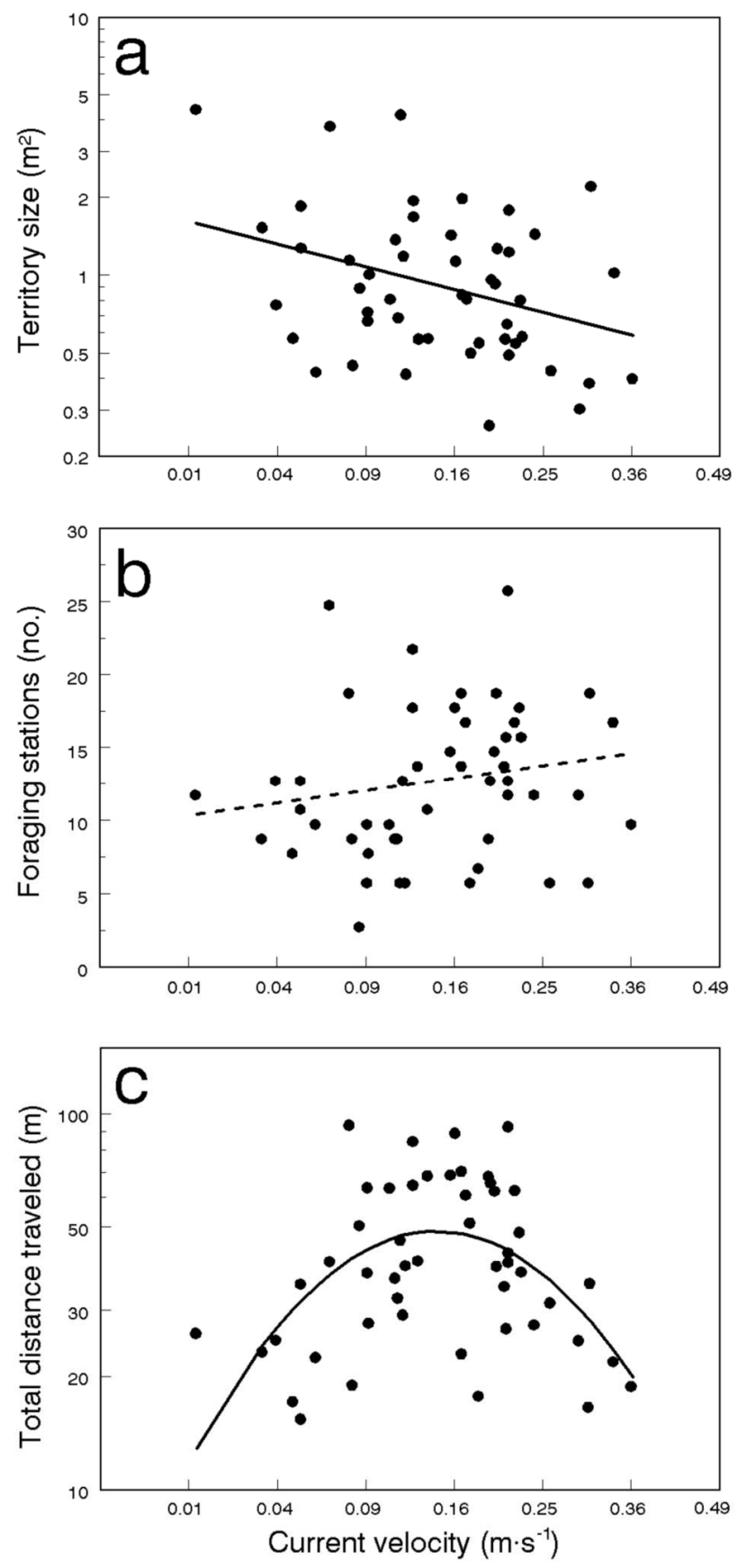

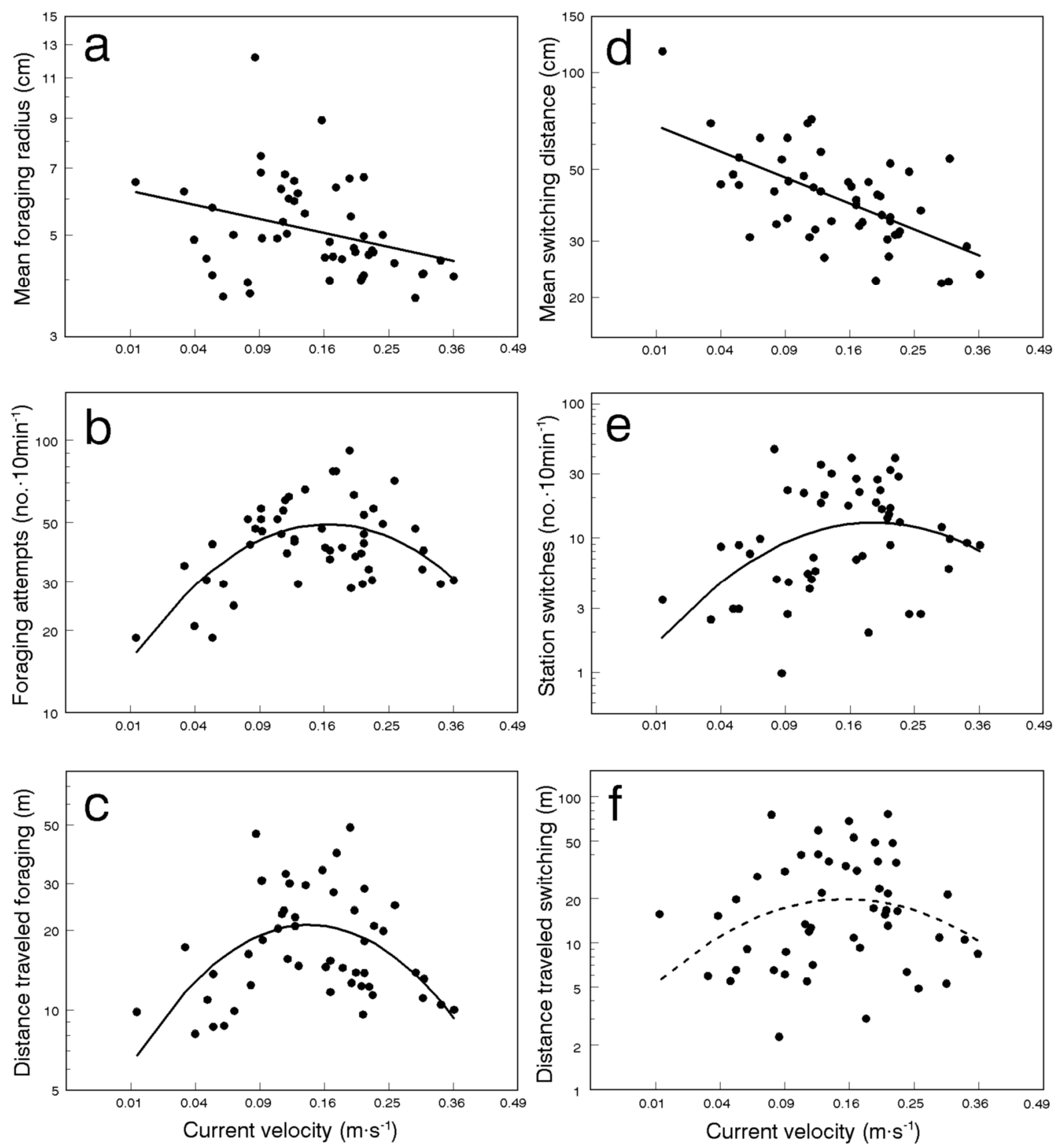

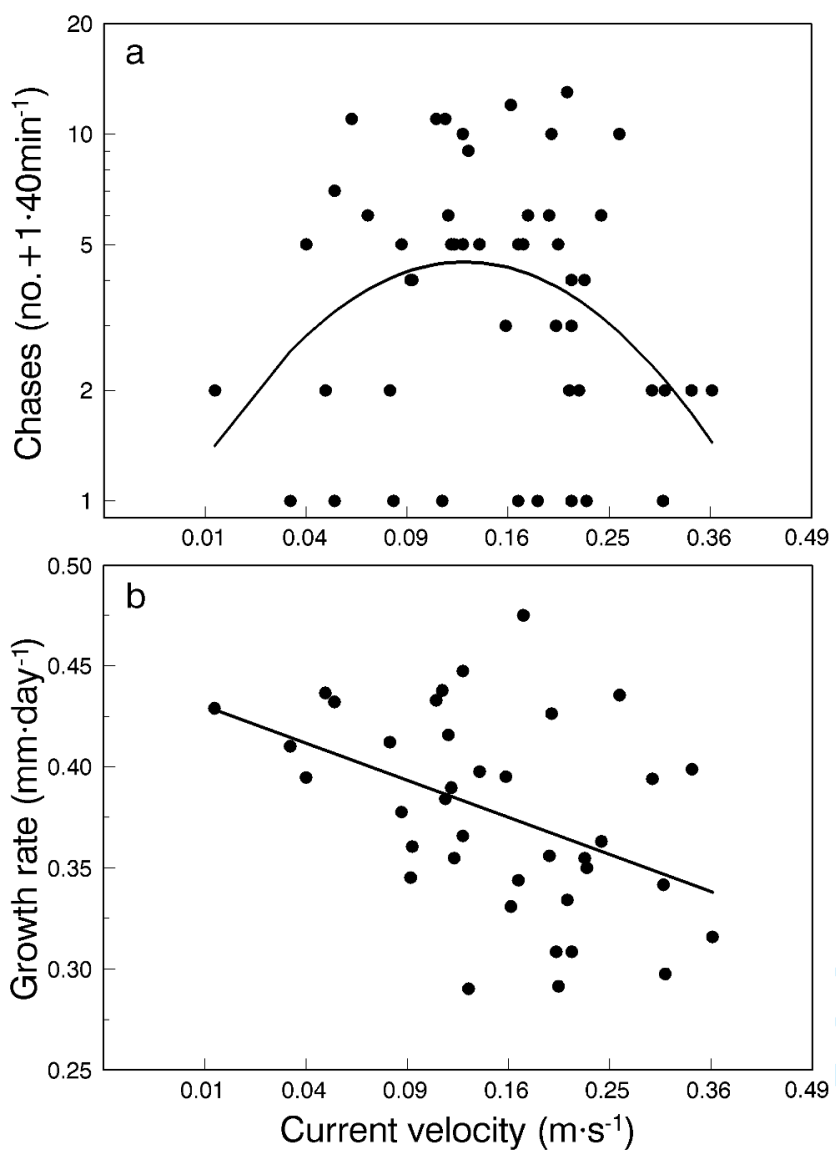